\title{
Psychological insulin resistance: scope of the problem
}

\author{
Andrea Luk *, FHKCP, FHKAM (Medicine) \\ Department of Medicine and Therapeutics, The Chinese University of Hong Kong, Prince of Wales Hospital, Shatin, Hong Kong \\ *andrealuk@cuhk.edu.hk \\ Hong Kong Med J 2016;22:304-5 \\ DOI: 10.12809/hkmj165025
}

Diabetes mellitus is a pandemic that is infiltrating our society in tandem with the rising prevalence of obesity. Based on population surveys, up to one in 10 people in China have diabetes and half have prediabetes with the majority of them undiagnosed. ${ }^{1}$ Diabetes reduces life expectancy by an average of 12 years and contributes to death in close to $10 \%$ of affected adults. ${ }^{2}$ Prevailing evidence indicates that diabetes-related vascular complications are highly preventable through intensive glycaemic and global risk factor management, and that optimisation of blood glucose early in the disease trajectory translates into latent benefits for decades beyond. ${ }^{3,4}$

Maintenance of optimal glycaemic control requires successive up-titration of antidiabetic drug treatment, and insulin is necessary for the majority of patients due to a natural progressive decline in pancreatic beta-cell function. Whilst international guidelines strongly advocate insulin supplementation upon failing two or three non-insulin antidiabetic drugs,${ }^{5}$ initiation of insulin therapy is often delayed as a result of clinical inertia and resistance by patients. ${ }^{6}$ In a survey of patients with type 2 diabetes who attended general practices in the United Kingdom, there was a time lag of 5 years to the commencement of insulin during which glycaemic control had remained unsatisfactory on two or more non-insulin agents. ${ }^{6}$ Refusal of insulin is commonly encountered and between $20 \%$ and $40 \%$ of insulin-naïve patients with type 2 diabetes express unwillingness to inject insulin when prescribed.-9 Furthermore, among existing insulin users, adherence to the prescribed regimen is suboptimal in up to one third of patients. ${ }^{10}$ Failure to initiate insulin therapy in a timely manner and to comply with the recommended injection doses and schedule are key factors that lead to low rates of glycaemic target attainment. Among participants of a multinational study that evaluated the quality of care of patients with diabetes in Asia, more than half of the enrolled patients did not reach the glycated haemoglobin $(\mathrm{HbA} 1 \mathrm{c})$ target of $<7.0 \%$, and the situation was worse in those with youngonset diabetes. ${ }^{11}$

Psychological insulin resistance is a phenomenon that describes barriers to starting insulin therapy and/or adhering to prescribed treatment. ${ }^{12}$ It encompasses a range of psychological factors that include fear of injection and/or pain, fear of hypoglycaemia and/or weight gain, poor self-efficacy about the skills required to administer insulin, anxiety over interference with daily living, anticipated social stigmatisation, and misconceptions about the rationale and efficacy of insulin therapy. Depending on the assessment method and clinical setting, psychological insulin resistance is detected in approximately $40 \%$ to $70 \%$ of patients. ${ }^{13,14}$

Culture, age, and gender are variables that may influence the scope of psychological insulin resistance. ${ }^{15}$ Based on studies conducted in western countries, the most important factor contributing to patients' reluctance to commence insulin therapy is the belief that insulin is not able to improve disease control and prognosis. ${ }^{16,17}$ Additionally, patients often perceive insulin therapy as a form of punishment for their personal failure to selfmanage their diabetes, a point that is reinforced by the physician when insulin therapy has previously been presented as a threat to motivate self-care. ${ }^{18,19}$ It is noteworthy that fear of injection or pain was infrequently reported in these populations. ${ }^{8}$ In a recent study of local Chinese patients with type 2 diabetes, patients' impression of insulin therapy was explored using the Chinese Attitudes to Starting Insulin Questionnaire. ${ }^{20}$ In contrast to observations in their western counterparts, Chinese patients, particularly females, were much more likely to fear needles and be apprehensive about pain associated with injection, whilst most were confident that insulin would improve their health outcome.

Fear of hypoglycaemia and weight gain is another critical factor that diminishes treatment satisfaction leading to compliance problems particularly among insulin users. In a survey of insulin-treated patients, frequent hypoglycaemia was reported in $40 \%$ and high fear score for hypoglycaemia in $15 \% .^{21}$ Predictors of fear of hypoglycaemia included young age, prior experience of severe hypoglycaemia, and perceived disruption of work life attributable to hypoglycaemia. ${ }^{21}$ It is not uncommon for patients to intentionally omit doses of insulin and/or eat excessively to avoid hypoglycaemia.

Despite a high prevalence, psychological insulin resistance is often under-recognised and inadequately addressed. Studies have demonstrated an association of psychological insulin resistance 
with high HbA1c. ${ }^{22}$ A link between depression and psychological insulin resistance has also been identified, suggesting that patients who carry negative emotions are less willing to start and to comply with insulin therapy. ${ }^{17,23}$ It may be that efforts to alleviate aversion to insulin therapy should be extended to tackling triggers of diabetes-related distress and other emotional concerns.

From a practical standpoint, when faced with patients' unwillingness to initiate insulin, the health care provider should encourage acceptance by exploring the underlying issues and managing concerns in a positive manner, in order to minimise unnecessary delay in treatment titration. In the current issue of the Hong Kong Medical Journal, Lee $^{24}$ examined the prevalence of psychological insulin resistance in a cross-sectional study of Chinese patients with type 2 diabetes who attended a general out-patient clinic in Hong Kong and assessed the validity and reliability of the Chinese version of the Insulin Treatment Appraisal Scale. Using this instrument, psychological insulin resistance was prevalent in about half of the study subjects. The author, however, also identified a translation problem in at least one of the 20 questions in the questionnaire that may limit its general use in clinical practice. Psychological insulin resistance is a common reaction in people with diabetes and obstructs the necessary transition from oral antidiabetic drug to insulin. Health care professionals who care for patients with diabetes should be alerted to the multi-dimensional nature of psychological insulin resistance and be equipped to attend to various concerns, ease ambivalence, and facilitate a pathway for timely and effective use of insulin therapy.

\section{References}

1. Xu Y, Wang L, He J, et al. Prevalence and control of diabetes in Chinese adults. JAMA 2013;310:948-59.

2. Roglic G, Unwin N, Bennett PH, et al. The burden of mortality attributable to diabetes: realistic estimates for the year 2000. Diabetes Care 2005;28:2130-5.

3. Intensive blood-glucose control with sulphonylureas or insulin compared with conventional treatment and risk of complications in patients with type 2 diabetes (UKPDS 33). UK Prospective Diabetes Study (UKPDS) Group. Lancet 1998;352:837-53.

4. Holman RR, Paul SK, Bethel MA, Matthews DR, Neil HA. 10-Year follow-up of intensive glucose control in type 2 diabetes. N Engl J Med 2008;359:1577-89.

5. Standards of medical care in diabetes-2016. Diabetes Care 2016;39(Suppl 1):S1-106.

6. Rubino A, McQuay LJ, Gough SC, Kvasz M, Tennis P. Delayed initiation of subcutaneous insulin therapy after failure of oral glucose-lowering agents in patients with type 2 diabetes: a population-based analysis in the UK. Diabet Med 2007;24:1412-8.

7. Polonsky WH, Fisher L, Guzman S, Villa-Caballero L, Edelman SV. Psychological insulin resistance in patients with type 2 diabetes: the scope of the problem. Diabetes Care 2005;28:2543-5

8. Larkin ME, Capasso VA, Chen CL, et al. Measuring psychological insulin resistance: barriers to insulin use. Diabetes Educ 2008;34:511-7.

9. Woudenberg YJ, Lucas C, Latour C, Scholte op Reimer WJ. Acceptance of insulin therapy: a long shot? Psychological insulin resistance in primary care. Diabet Med 2011;29:796802.

10. Doggrell SA, Chan V. Adherence to insulin treatment in diabetes: can it be improved? J Diabetes 2015;7:315-21.

11. Yeung RO, Zhang Y, Luk A, et al. Metabolic profiles and treatment gaps in young-onset type 2 diabetes in Asia (the JADE programme): a cross-sectional study of a prospective cohort. Lancet Diabetes Endocrinol 2014;2:935-43.

12. Peyrot M. Psychological insulin resistance: overcoming the barriers to insulin therapy. Pract Diabetol 2004;23:6-12.

13. Jenkins N, Hallowell N, Farmer AJ, Holman RR, Lawton J. Participants' experiences of intensifying insulin therapy during the Treating to Target in Type 2 Diabetes (4-T) trial: qualitative interview study. Diabet Med 2011;28:543-8.

14. Wong S, Lee J, Ko Y, Chong MF, Lam CK, Tang WE. Perceptions of insulin therapy amongst Asian patients with diabetes in Singapore. Diabet Med 2011;28:206-11.

15. Fitzgerald JT, Gruppen LD, Anderson RM, et al. The influence of treatment modality and ethnicity on attitudes in type 2 diabetes. Diabetes Care 2000;23:313-8.

16. Polonsky WH, Hajos TR, Dain MP, Snoek FJ. Are patients with type 2 diabetes reluctant to start insulin therapy? An examination of the scope and underpinnings of psychological insulin resistance in a large, international population. Curr Med Res Opin 2011;27:1169-74.

17. Snoek FJ, Skovlund SE, Pouwer F. Development and validation of the insulin treatment appraisal scale (ITAS) in patients with type 2 diabetes. Health Qual Life Outcomes 2007;5:69.

18. Polonsky WH, Jackson RA. What's so tough about taking insulin? Addressing the problem of psychological insulin resistance in type 2 diabetes. Clin Diabetes 2004;22:147-50.

19. Brod M, Kongsø JH, Lessard S, Christensen TL. Psychological insulin resistance: patient beliefs and implications for diabetes management. Qual Life Res 2009;18:23-32.

20. Fu SN, Wong CK, Chin WY, Luk W. Association of more negative attitude towards commencing insulin with lower glycosylated hemoglobin (HbA1c) level: a survey on insulinnaïve type 2 diabetes mellitus Chinese patients. J Diabetes Metab Disord 2016;15:3.

21. Shiu AT, Wong RY. Fear of hypoglycaemia among insulintreated Hong Kong Chinese patients: implications for diabetes patient education. Patient Educ Couns 2000;41:251-61.

22. Fu AZ, Qiu Y, Radican L. Impact of fear of insulin or fear of injection on treatment outcomes of patients with diabetes. Curr Med Res Opin 2009;25:1413-20.

23. Makine C, Karşidağ C, Kadioğlu P, et al. Symptoms of depression and diabetes-specific emotional distress are associated with a negative appraisal of insulin therapy in insulin-naïve patients with type 2 diabetes mellitus. A study from the European Depression in Diabetes [EDID] Research Consortium. Diabet Med 2009;26:28-33.

24. Lee KP. Validity and reliability of the Chinese version of the Insulin Treatment Appraisal Scale among primary care patients in Hong Kong. Hong Kong Med J 2016;22:306-13. 